\title{
The Quant Delusion: Financial Engineering in the Post-Lehman Dodd-Frank Landscape
}

\section{Citation}

Blyth, Stephen. 2012. The Quant Delusion: Financial Engineering in the Post-Lehman DoddFrank Landscape. CFA Institute Conference Proceedings Quarterly 29 (1): 1-8.

\section{Published Version}

doi:10.2469/cp.v29.n1.6

\section{Permanent link}

http://nrs.harvard.edu/urn-3:HUL.InstRepos:11878778

\section{Terms of Use}

This article was downloaded from Harvard University's DASH repository, and is made available under the terms and conditions applicable to Open Access Policy Articles, as set forth at http:// nrs.harvard.edu/urn-3:HUL.InstRepos:dash.current.terms-of-use\#OAP

\section{Share Your Story}

The Harvard community has made this article openly available.

Please share how this access benefits you. Submit a story.

Accessibility 


\section{The Quant Delusion: Financial Engineering in the Post-Lehman Dodd-Frank Landscape Stephen Blyth}

Managing Director and Head of Internal Management

Harvard Management Company

Boston

Stephen Blyth is managing director and head of internal portfolio management at Harvard Management Company. Previously, he was managing director and head of the global rates proprietary trading group at Deutsche Bank in London and managing director in the interest rate group at Morgan Stanley. Professor Blyth is also Professor of the Practice in Statistics at Harvard University where he teaches applied quantitative finance, and he has published a number of articles in academic and industry journals. He holds an MA degree in mathematics from Christ's College, University of Cambridge, where he is a Lady Margaret Beaufort Fellow, and a PhD in statistics from Harvard University.

This presentation comes from the Fixed-Income Management 2011 conference held in Boston on 13-14 October 2011 in partnership with the Boston Security Analysts Society, Inc.

Editor's Note: The opinions or recommendations expressed in this article are those of the author and are not representative of Harvard Management Company as a whole.

The recent financial crisis and its aftershocks have reshaped the world of financial engineering, quantitative analysis, and derivatives trading. Government intervention, regulatory reform, and the refutation of fundamental axioms and model assumptions are three reshaping forces now confronting quantitative practitioners.

In 1993, the U.S. Congress canceled the Superconducting Super Collider (SSC) project. At an estimated cost of $\$ 12$ billion, the project would have created the largest linear particle accelerator in the world and would likely have provided 
years of employment for large numbers of physicists in the United States. But after the cancellation, the job market for academic physicists collapsed and many moved into finance and quantitative analysis.

This generation of quantitatively trained analysts (quants) - the SSC generation-catalyzed a remarkable growth of financial engineering and quantitative analysis. The 20 years following the cancellation of the SSC witnessed a flurry of technological and computational advances that led to increasingly sophisticated modeling and analytical capabilities. These advances were coupled with growth in financial markets-growth in volume, sophistication, complexity, and depth of traded products, especially in derivatives markets. The universe of traded products grew dramatically with only a few setbacks: for example, the Orange County debacle in 1993 and the Russian debt crisis and the collapse of Long-Term Capital Management in 1998.

The purpose of this presentation is to examine three forces that are now reshaping the landscape engineered by the SSC generation during the past 20 years:

1. Empirical challenges to basic logical arguments of quantitative finance

2. Government intervention

3. Regulatory reform

\section{Three Reshaping Forces}

The three forces reshaping the financial markets each have distinct characteristics, yet there is interplay among them, and all are still playing out.

Market phenomena that investors have experienced in the last three years have shaken laypeople and practitioners alike. Practitioners are having to reconsider how they assess value, manage risk, set bounds and order prices, and conduct relative value. On occasion, they have been stunned by the phenomena they have observed in the market. These experiences have led to 
empirical lessons that reach beyond the tactical level of simply replacing one conventional model with another. These lessons represent foundational challenges to basic statements of logic that practitioners have been using in quantitative fixed income for decades.

The second force, which was catalyzed by the crisis itself, is government intervention and policy reaction. Since the initial responses in 2007-for example, the extension of the discount window in August 2007-a whole suite of unusual responses has followed and is continuing to evolve. Such responses are affecting the assessment of value in markets generally but especially in fixed-income markets.

Regulatory reform, the third reshaping force, is a complicated and difficult topic. The Dodd-Frank Act and Basel III are shifting the landscape for derivative products and other fixed-income investments and thus changing the way investors think about value opportunities and the exploitations of mispricing in this universe.

I view the new landscape as one that is undergoing tectonic shifts. It is not yet clear which buildings will be fit to reinhabit after this shift, but we are certainly operating in a significantly reshaped investment space.

For example, in 2003 Mark Joshi wrote that "if we pick the right government, this possibility [of government default] is sufficiently remote that we can for practical purposes neglect it. If this seems unreasonable, consider that if the British, American, or German government reached such straits, the world's financial system would be in such a mess that there would be precious few banks left to employ financial mathematicians." ${ }^{1}$ Yet, the risk of government default is now at the heart of fixed-income markets, and Joshi's assertion reflects well the mindset of many practitioners within the quantitative investment space before the crisis.

${ }^{1}$ Mark S. Joshi, The Concepts and Practice of Mathematical Finance (Cambridge: Cambridge University Press, 2003): 1. 
Such practitioners were operating as if the 15- to 20-year dataset that they had experienced in their own careers essentially incorporated the universal set of all possible outcomes. They have learned that this view is not accurate. The actual universe of possible outcomes and price action is vastly different from that which people have experienced in the past 20 years. The limited set of data and the limited experience of market participants are combined with products that themselves have only existed for a similarly short period. For example, the first recorded swap occurred in 1981 between the World Bank and IBM, and reliable data have been available only since the 1990s.

At a broad level, the financial world experienced a misspecification of the set of possible outcomes. People were spending energy on quantitative modeling and being precise about their models conditional on the world of the previous 20 years essentially continuing into the future. That practice was rendered useless once investors realized that the set of possible outcomes was far larger. Throughout the Lehman Brothers crisis, for example, fundamental and logically sound arguments were challenged and found inadequate, thus forcing practitioners to reassess how they manage risk and make investment decisions.

\section{Empirical Challenges to Fundamental Arguments}

Three examples illustrate the challenges that confronted practitioners and their assumptions about price action and market behavior:

1. The conundrum of uncollateralized versus collateralized funding rates

2. Arbitrage within off-balance-sheet derivatives markets

3. Violation of the triangle inequality

Collateralized vs. Uncollateralized Funding. The conundrum of collateralized versus uncollateralized funding can be seen in the Treasury and swap markets. The argument is that collateralized funding, particularly that 
secured by government debt, should be cheaper than uncollateralized funding, as measured by LIBOR rates. The rate for uncollateralized funding must be higher because if market participants could borrow more cheaply on an uncollateralized basis than collateralized basis then they could simply opt to keep their Treasury collateral.

Simple logic thus concludes that LIBOR rates must be higher than repo rates, which has indeed been true. In Figure 1, I show that the Treasury Eurodollar (TED) spread, which is the difference between three-month LIBOR and the three-month T-bill interest rate (a good proxy for repo rates), has always been positive; indeed, it tends to widen in times of financial stress. This fundamental logical argument-uncollateralized funding is at a higher rate than collateralized funding-predicated trading for the 20 years before the crisis.

We can now construct a straightforward trade in Treasury, repo, and swap markets that builds on this logic. An investor buys a Treasury bond and obtains repo financing for the Treasury bond from a repo counterparty. As illustrated in Exhibit 1, the investor also enters into an interest rate swap of matched maturity to the Treasury bond against LIBOR. When this trade is collapsed down, the investor is net receiving LIBOR less the repo rate on the floating side, which by the argument earlier must be positive. Furthermore, on the fixed side the investor is paying the swap rate less the bond yield, which is known as the swap spread. Because the investor is receiving a positive quantity and paying the swap spread, the conclusion is that the swap spread must be positive or else there is an arbitrage. This straightforward logical argument that swap spreads must be positive was taken for granted until 2008.

From the inception of liquid swap markets until 2008, the 30-year swap spread was indeed positive, as Figure 2 shows. Then, a month after Lehman Brothers collapsed, the spread moved negative, going down to nearly $-50 \mathrm{bps}$, and it remains negative as of late 2011, even as other markets have normalized. Something in this foundational argument has failed. 
Market participants have spent much time in recent years trying to explain why the swap spread is negative. Reasons put forward include increased financing haircuts, balance sheet constraints, supply of government debt, reduction of risk appetite and mark-to-market tolerance, and in particular, deterioration of U.S. sovereign credit. These are all plausible arguments, but they were not being made in 2007, and a completely satisfactory answer has not yet been reached.

Off-Balance-Sheet Arbitrage. Two further compelling examples come from derivatives activities in which there are no explicit balance-sheet constraints.

First, consider options on swaps (called "swaptions") in the interest rate derivatives market. The most basic style is the European swaption, which has one exercise date to enter into a swap. Another style is called the "Bermudan swaption" (or "American swaption"), which allows for multiple exercise dates to enter into a swap. Because a Bermudan swaption offers more optionality, it is in theory more valuable than a European swaption. To prove this bound, assume that it does not exist and construct an arbitrage portfolio. For example, if I can buy a Bermudan swaption more cheaply than I can sell a European swaption, identical in all terms other than the multiple exercise dates, then I have been paid to enter a portfolio whose payout is always bounded below by zero.

Now, consider an interest rate floor versus a Bermudan swaption. An interest rate floor is, in essence, the sum of a number of options for each subperiod of a swap. If I match an interest rate floor with the strike prices, dates, and expiration details of a Bermudan receiver swaption, a similar argument shows that the interest rate floor must have greater value than the Bermudan. If not, I can construct an arbitrage portfolio.

Such conclusions arise from fundamentally sound logical arguments that have ordered the value of products since derivatives markets began. But after Lehman Brothers collapsed, investors were able to buy an interest rate floor 
cheaper than the exact matched Bermudan swaption, thus violating the bounds that had previously always held. The reason for this violation of bounds is not clear. Perhaps it was because of the long-dated nature of the trade or a broad reduction of risk appetite. Whatever the cause, fundamental bounds no longer held and the market was unsettled.

Violation of Triangle Inequality. The third example relates to the triangle inequality, which states that the sum of the lengths of any two sides of a triangle must be greater than or equal to the length of the remaining side. Disturbing violations of this inequality began to occur after Lehman Brothers collapsed.

For example, consider two call options on Asset A and Asset B. Let the first option have strike price $K_{1}$ and value $X$, and the second have strike $K_{2}$ and value $Y$. Now, consider a third call option on asset $A+B$ with strike $K_{1}+K_{2}$ and value $Z$. An inspection of payouts shows that it must have the triangle inequality $X+Y \geq Z$. If not, then arbitrageurs can buy the first two options, sell the third, and construct an arbitrage portfolio.

After Lehman Brothers' collapse, however, investors were able to buy an option on an underlying (such as a 2-year interest rate), buy an option on the 10-year interest rate minus the 2-year interest rate, and sell an option on the 10-year rate, collecting premium upfront and matching all strikes and maturities. This example thus violated the triangle inequality.

No Axiom of Choice. The current situation is challenging for both quants and derivatives investors because neither is now certain about how to order prices, let alone assess value. An analogy from mathematics may be helpful in explaining the new landscape. At the heart of logic is the "Axiom of Choice," which involves certain assumptions about choosing elements from an uncountable, infinite number of sets. The Axiom of Choice is required for particular properties of the real numbers to hold-for example, the well- 
ordering of the real numbers. Without the Axiom of Choice, mathematics can still be done, but it becomes far messier.

The landscape of quantitative finance today is the equivalent of mathematics without the axiom of choice. As shown in the examples earlier, certain basic ordering of prices no longer holds. In such an environment, quantitative products still exist, but derivatives pricing, model building, and risk management become far more complex.

\section{Government Intervention}

Government response to the 2008 financial crisis led to massive intervention in public markets that initially alleviated several problems. Liquidity and market functionality were returned to several sectors, and panic levels regarding the systematic risk of corporate default were reduced significantly. Two programs were especially effective. The Temporary Liquidity Guarantee Program (TLGP) targeted the funding of banks, which were subsequently able to resume taking intelligent risks. Quantitative Easing $(\mathrm{QE})$, particularly $\mathrm{QE} 1$, normalized the Treasury market, which then helped restart risk taking as private investors observed government capital being applied to sensible trades.

In a case at Harvard Business School, we discussed dislocation in the Treasury market in late 2008 and early 2009, and how that shaped the evolution of government intervention. Treasuries of the same maturity were trading $70 \mathrm{bps}$ apart. Clearly, investors were not going to be buying more structured or exotic assets in that situation. The Troubled Asset Relief Program (TARP) was doomed in its initial format, when Treasury bonds themselves offered tremendous relative value but there was no risk capital available. No one was willing to go down the risk spectrum at that time.

But the combination of TLGP and QE1 suggested that the government was behaving in a rational and deliberate manner. First, it was involved in Treasury relative value itself, buying cheap bonds. Second, it was providing access to funding for banks who could themselves get involved in these trades. 
These steps normalized the market and promoted a cascade of risk taking down the risk spectrum, flowing through Treasuries, Treasury InflationProtected Securities (TIPS), mortgages, and then into stocks.

In contrast to the treasury market, some markets in 2009 were overwhelmed by government intervention. A stressed mortgage market was initially normalized by QE1 purchases, but the size of the program was so vast that the mortgage market then shifted from being normalized to being stressed again as investors were confronted by delivery and financing issues. Thus, overwhelming government intervention distorted traditional assessments of value in the mortgage market.

A second phase of the crisis has now developed and fears are rising that the global economy is entering a European version of a Lehman-like collapse. Government intervention has itself moved into a new phase of remarkable extension of accommodation. For example, vast government intervention has occurred along the yield curve in the form of QE3 (the Federal Reserve's "operation twist"). Yet, one has to question whether QE3 is as sensible as QE1. Investors find it difficult to appraise a market in which more than $\$ 400$ billion of long-dated treasuries are being bought by the government. I am less optimistic that the current intervention will normalize markets and restore confidence in a manner as effective as 2009.

Unusual government intervention that is challenging other bounds of quantitative finance is occurring elsewhere around the world. For example, the Swiss franc market is experiencing empirical price action that challenges standard logical reasoning. Following significant Swiss National Bank intervention, interest rates have been negative for several months. A one-year swap rate of $-25 \mathrm{bps}$ is a challenge to most usual logical assumptions.

\section{Regulatory Reform}


The third reshaping force is market regulation that is currently in an extensive rule-making process with many complex pieces of legislation. All institutions are involved in trying to assess the impact of the reforms.

As a special entity, Harvard Management Company (HMC) is in an interesting position. There was initially a possibility, no longer likely, that dealers might have to owe us a fiduciary responsibility, which is not what a professional investor would want. The key overriding characteristic of the current regulatory environment is great uncertainty. The debate itself seems to have moving goalposts or even moving playing fields.

A certain amount of delay and pushback on rule making has occurred, but it remains likely that significant changes will be made that affect how investors can trade. Uncertainty remains about risk-taking ability and incentive within financial institutions. For example, the Volcker Rule reduces the amount of risk allowed to be taken systemwide. Furthermore, substantial changes have occurred in margining, clearing, and reporting requirements. Margining requirements for uncleared trades in particular will change the capital costs of doing trades and thus reshape markets.

Many aims of the regulatory process are highly sensible. One is to collapse $\$ 450$ trillion of derivatives down to its vastly smaller net amount, thus significantly reducing systemic risk in the case of a bankruptcy. A second aim is to require appropriate capitalization of derivatives trading activities. As the rules are rewritten for capital requirements and margining, however, some participants may find it is no longer viable to trade in this space or that certain strategies are no longer viable. For example, banks have already stopped making markets in certain sectors of interest rate markets.

One of the intellectual appeals of finance is the quest to discover a structure or risk that seems dislocated (perhaps because of retail flows or market segmentation) around which a compelling trade opportunity can be constructed-not necessarily just in duration space but in higher order parameters, such as volatility or correlation. Risk that becomes dislocated or mispriced presents opportunities for well-capitalized investors seeking returns 
and outperformance. HMC's investment performance is judged relative to an asset allocation or policy portfolio. We thus care about the outperformance or "alpha" opportunity set, and we know this set may shrink in certain ways, if only because there will be reduced dimensionality of traded products. The SSC generation has seen only increases in the set of traded products during the past 20 years and we are now seeing a retrenchment. The participant set in this smaller world, however, may also be shrinking because of less leverage, less risk taking, and increased capital requirements generally.

Capital requirements for uncleared trades have yet to be set, but oddities seem likely to occur. For example, in a bilateral derivatives transaction the risk is symmetrical between the client and the dealer. Currently, an institution like HMC will have to post initial margin on a transaction to the dealer (and not the other way round) even though the dealer may have a significantly lower credit rating. This requirement would only increase credit exposure to a lower rated counterparty, which may cause highly rated institutions to withdraw from the market thus reducing market liquidity.

Whether regulatory reform will lead to an alpha deprivation or an alpha dividend is a question integral to quantitative investment managers. If certain investment spaces cease to exist, some quants may need to put down their calculators and retrain.

\section{Navigating the New Landscape}

Uncertainty is the primary characteristic of the new investment landscape. Investors need to assess probabilities, make investment decisions, and manage risk within a much larger conditioning set of possible outcomes. Ranking a scoreboard of possible trades by attractiveness and by the best place to put capital at risk is now significantly harder.

Market participants can no longer rely on certain logical arguments. At the very least, they will have to adjust statements of relative value because past relationships they had taken for granted may not always hold. Furthermore, 
governments are making large interventions that may or may not be deemed rational and that will likely swamp private investors. Even the simply stated question of where yields should be has become much harder to answer.

Finally, investors must be prepared to fathom and adapt to a new regulatory framework. For example, an attractive trade that now involves increased margining to a lower-rated counterparty may no longer make sense. The attractiveness of a trade with arbitrage characteristics may also be affected by the fact that liquidity in relevant markets may evaporate. Perhaps many more markets will go the way of the Japanese inflation-linked bond market, of which all that remains is a vestigial market. Investors are understandably cautious.

Conversely, we may now begin to observe a richer set of possible opportunities arising from the interplay of government regulation, government policy, and the strange and messier market that now exists. 


\section{Question and Answer Session}

\section{Stephen Blyth}

Question: How widely accepted in the industry is this view of reshaping forces?

Blyth: Views among sell-side CEOs and heads of divisions are nuanced and can vary widely. Some industry leaders agree that the model is changing, that return on equity must unavoidably be lower, that capital ratios will have to be better, and that compensation will be lower.

They are ready to embrace the change. Others believed until recently that current conditions are more of a blip (a major blip) and that the markets will soon revert to the more levered model and trading of the early 2000s. This second view is unrealistic to me. Overall, today I see views that are more realistic than at the end of 2009.

Question: What are your thoughts on forward-looking scenario analysis?

Blyth: I am skeptical of scenario analysis as a panacea because it depends on the scenarios chosen and the response function to these scenarios. Analysts can run as many scenarios as they like, but if they do not consider how the institution might respond, then the analysis is not that helpful. For example, one might run a scenario of equity markets being down 30 percent, under which an investment portfolio is down 25 percent. This analysis may not be particularly informative.

We should not restrict ourselves to the historical dataset, and we should certainly not be tempted to assume, because conditions seem more stable now, that the maxima and minima of 2008-2009 are global maxima and minima. Many former hedge fund strategies were predicated on the idea that conditions could never get worse than the extremes of the Long-Term Capital Management 
collapse in 1998. Now, some investment managers are saying that conditions will never be worse than the Lehman collapse. Unfortunately, a lot of situations present worse possibilities than the financial crisis.

So, investors have to be creative in accepting the strange things that have happened and additional ones that could happen. This concept is in some sense the subtext of this presentation: We should not build a new investment process conditional on now knowing the extremes.

Question: What are your thoughts about behavioral finance as opposed to quantitative finance?

Blyth: I am agnostic. Finance is all about people making decisions and learning from experience, and those things are subjective. Even statistics as a discipline is subjective because whatever tool one uses, decisions are being made based on experience, interpretations of data, choice of statistical method, and choice of dataset. Experience and judgment play a role, regardless of the quantitative toolkit one uses.

Sometimes sophisticated quantitative models inform the decision process; sometimes the models used are less sophisticated. A subjective element always exists, even in algorithmic funds. Ultimately, people decide which models to put in their algorithmic funds and how and when to switch them on and off. Subjectivity is intrinsic.

Question: What are your thoughts on the hedge fund industry and the implications for investors who have placed money with third-party managers?

Blyth: There was a shakeout on the buy side following the crisis. For example, a middle tier of fixed-income, relative-value funds no longer exists. Large multistrategy and macro funds have been more successful. There have been relatively few new participants with varying degrees of success. 
Participation in more complex, higher-dimensional strategies is lower, with a migration of risk toward exchange-traded and more liquid products. That seems to be a natural response to the liquidity evaporation. Fewer players seem to exist in some areas where HMC has expertise, which may create an alpha dividend for us.

Overall hedge funds seem to have been more stable in this environment than one might have expected.

Question: Do we need a market maker of last resort?

Blyth: We certainly did not initially have a coordinated response in 2008 , but it evolved into something that was effective. Because the crisis was occurring during a handover between administrations, a strange bipartisanship occurred that became surprisingly effective.

Unfortunately, political conditions are now quite different. I spend a lot of time trying to explain why the debt ceiling brinkmanship of 2011 was so devastating for market confidence. It was hard for people to understand that market participants were naturally going to respond to such brinkmanship with the sale of risk assets, even though the final agreement was not far from what one might have expected a priori.

The concept of a market maker of last resort is quite useful, and the U.S. government essentially acted effectively in that role in early 2009. The government issuing debt essentially for free when T-bill rates were zero and buying cheap liquid assets like Treasuries is acting like a well-run hedge fund. It is quite appealing because it obviously stabilizes and normalizes markets and it catalyzes private risk taking.

Such a market maker on a global level is more difficult to imagine. It certainly seems unfeasible to me. Consider the debate about the Fed's operation twist and the heated language now being used. In a world full of autonomous democracies, a globally funded response is probably implausible. 
Question: Many prominent investors have labeled derivatives "weapons of mass destruction." Can such a statement become a self-fulfilling prophecy?

Blyth: I expect regulation to address appropriate capitalization of derivatives. The concept of being able to enter into a derivative trade without appropriate capital charge will likely be a thing of the past.

Complexity is another important issue. The market developed sophisticated derivative models but these can become detached from the products. Investors must remember that derivative products are priced according to the primal supply and demand of the market, and not according to a model. When this break becomes large, the potential for destruction is great. Add size and high leverage, and mass destruction is possible.

Question: Considering that HMC is rated higher than most counterparties, how do you feel about counterparty risk management and counterparty collateral management?

Blyth: Like most institutions, we value the clearing process if the exchange is suitably capitalized.

We care about mark to market and collateralization with each counterparty, but we also care about our risk exposure to each counterparty given that at the instant of default we have significant gap risk to the risk replacement process, even if adequately collateralized to current valuations. 